“ (C) 2017 IEEE. Personal use of this material is permitted. Permission from IEEE must be obtained for all other uses, in any current or future media, including

reprinting/republishing this material for advertising or promotional purposes, creating new collective works, for resale or redistribution to servers or lists, or reuse of any copyrighted component of this work in other works." 


\title{
Design of a Lock-in Amplifier Integrated with a Coil System for Eddy-Current Non-Destructive Inspection
}

\author{
Fredy Munoz, Jaime Valls Miro, Gamini Dissanayake, Nalika Ulapane, Linh Nguyen \\ University of Technology Sydney, Australia
}

Emails: Fredy.Munoz@uts.edu.au,Jaime.VallsMiro@uts.edu.au, Gamini.Dissanayake@uts.edu.au, Nalika.Ulapane@uts.edu.au,VanLinh.Nguyen@uts.edu.au

\begin{abstract}
Eddy-current non-destructive inspections of conductive components are of great interest in several industries including civil infrastructure and the mining industry. In this work, we have used a driver-pickup coil system as the probe to carry out inspection of ferromagnetic plates. The specific geometric configuration of the probe generates weak electric signals that are buried in a noisy environment. In order to detect these weak signals, we have designed and implemented a lock-in amplifier as part of the signal processing technique to increase the signal-to-noise ratio and also improve the sensitivity of the probe. We have used Comsol as a finite element method (FEM) to design the probe and conducted experiments with the probe and the lockin amplifier. The experimental results, which are in agreement with the FEM results, indicate that the designed probe along with a lock-in amplifier can potentially be used to estimate the thickness of thin plates while reducing the effects of the liftoff on the measurements.
\end{abstract}

\section{INTRODUCTION}

The detection of defects such as cracks in critical metal structures and the assessment of the condition of metallic water mains are commonly performed by using Eddy-current nondestructive inspection (NDI) [1-7]. In this technique, a coil excited with alternating current, called driver coil, is placed above the metal component in which eddy currents are induced. A second coil, called pickup coil, is also placed above the component to measure changes in the voltage across the pickup coil. These changes in the voltage carry information about the defects and the thickness of the metal component.

Different geometrical configurations, coil shapes and orientations are possible with a driver-pickup coil system. For instance, the analysis of six different high-symmetry configurations, including the pancake coil geometry, for cylindrical coils is presented in [8]. Although the analysis and implementation of driver-pickup coil systems have been extensively reported to work on homogeneous metal components such as steel, limited work has been reported on ferromagnetic components such as cast iron which can be highly heterogeneous [9]. In this work, we focus on the condition assessment of cast iron components by using Eddy-current NDI. Specifically, we aim to estimate the thickness of cast iron components from the voltage measured across a pickup coil.
A probe consisting of a driver-pickup coil system arranged in a pancake geometry is the most widely used in practice and is the probe that we have adopted in this work. In this configuration for air-cored cylindrical coils, we exploit the separation distance to improve the sensitivity of the probe while reducing the effect of the coil liftoff. However, as the separation of the coils is increased, the voltage received at the pickup coil becomes weaker and the signal-to-noise ratio (SNR) deteriorates.

In order to improve the SNR and the sensitivity of the probe to changes in the thickness of the cast iron component, we propose the use of a lock-in amplifier. Other signal processing techniques, such as homomorphic filter and pulse compression, have been reported in the literature to improve the SNR and enhance the detection reliability [10-11]. However, these techniques are usually more complex than lock-in amplifiers. Therefore, the main objective of this work is to determine whether a lock-in amplifier is sufficient to improve the SNR and the sensitivity of the specific probe that we have designed to conduct NDI.

The remainder work is organized as follows. Section II provides a description of the driver-pickup coil system that is used as a probe to measure the thickness of cast iron components. The details of the lock-in amplifier, as a signal processing technique, are presented in Section III. Experimental results of the probe and the lock-in amplifier are presented in Section IV. Finally, the significance of the results and future work are discussed in Section V.

\section{THE DRIVER-PICKUP COIL SYSTEM}

The driver-pickup coil system consists of a pair of cylindrical air-cored coils that are placed above a cast iron plate as shown in Fig. 1. The plate is large enough so that edge effects are minimized. In this work, we focus on metallic plates that have a non-ferromagnetic insulation layer of $10 \mathrm{~mm}$ in thickness.

The driver coil has 300 turns, $\mathrm{a}_{1 \mathrm{~d}}: 25 \mathrm{~mm}, \mathrm{a}_{2 \mathrm{~d}}: 31 \mathrm{~mm}$, height $\left(\mathrm{h}_{2 \mathrm{~d}}-\mathrm{h}_{1 \mathrm{~d}}\right): 10 \mathrm{~mm}$, wire diameter: $0.2 \mathrm{~mm}$, and is excited with 10 $\mathrm{V}$ at $10 \mathrm{~Hz}$. The pickup coil has 200 turns, $\mathrm{a}_{1 \mathrm{p}}: 14 \mathrm{~mm}, \mathrm{a}_{2 \mathrm{p}}: 22$ $\mathrm{mm}$, height $\left(\mathrm{h}_{2 \mathrm{p}}-\mathrm{h}_{1 \mathrm{p}}\right): 5 \mathrm{~mm}$, wire diameter of $0.2 \mathrm{~mm}$. The distance $\mathrm{d}$ between the centre of the coils is changed to improve 
the sensitivity of the probe and reduce the effect of the liftoff on the measurements. The liftoff of the two coils is the same (i.e., $\mathrm{h}_{1 \mathrm{~d}}=\mathrm{h}_{1 \mathrm{p}}$ ) and can vary from $10 \mathrm{~mm}$ to $20 \mathrm{~mm}$. The total voltage across the pickup coil can be described as $\mathrm{V}_{\mathrm{r}}(\mathrm{t})=\mathrm{V}_{\mathrm{s}}(\mathrm{t})+\mathrm{n}(\mathrm{t})$, where $\mathrm{V}_{\mathrm{s}}(\mathrm{t})$ represents the signal that varies with the liftoff and thickness of the inspected plate and $n(t)$ represents electrical noise in the system.

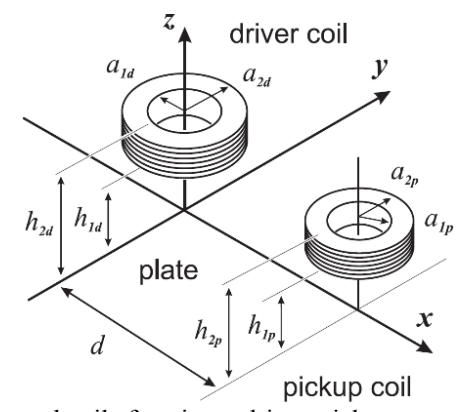

Fig. 1. Pair of air-cored coils forming a driver-pickup system above a cast iron plate with a thickness $\mathrm{c}$ protected by a $10 \mathrm{~mm}$ thick insulation layer

We are interested in measuring the amplitude, A, and phase, $\emptyset$, of the voltage $V_{s}$ as the liftoff and thickness of the plate, $c$, vary. For this reason, we built a lock-in amplifier that allows us to measure $V_{s}=A \sin (\omega t+\emptyset)$ in steady state that is buried in a noisy environment (i.e., $\mathrm{n}(\mathrm{t})$ ) and the experimental results are presented in Section IV. Prior to the experimental results, we have also used a FEM solution (Comsol Multiphysics) for a quick design and prototype of the probe and the results are presented as follows.

We have used a 2D axisymmetric model with the driver coil's axial axis coinciding with the $\mathrm{Z}$ axis and the bottom of its rectangular cross section (i.e., the liftoff) varies from 10 to 20 $\mathrm{mm}$ (see Fig. 2). The conducting plate is simulated with a large disk-shaped cast iron plate the thickness of which can vary from $3 \mathrm{~mm}$ to $15 \mathrm{~mm}$. The driver coil is simulated with copper (electrical conductivity $\sigma=5.9 \mathrm{e} 7 \mathrm{~S} / \mathrm{m}$ and magnetic permeability $\mathrm{u}_{\mathrm{r}}=1$ ) and the conducting plate with cast iron (electrical conductivity $\sigma=2.7 \mathrm{e} 6 \mathrm{~S} / \mathrm{m}$ and magnetic permeability $u_{r}=60$ ). We only simulate the driver coil in a $2 D$ axisymmetric model because this model provides sufficient results to achieve our goals in this paper. However, both coils can be also simulated in a 3D model to improve accuracy in the results at the expense of longer computational time.

We estimate changes in the amplitude of $B_{z}$ along the line $L$ due to changes in the liftoff and the thickness $\mathrm{c}$ of the conducting plate. Therefore, the line $\mathrm{L}$ represents the separation distance $\mathrm{d}$ between the two coils and the system is simulated assuming steady state (thus we use a frequency domain analysis in our simulations). The approximate magnitude of $\mathrm{V}_{\mathrm{s}}$ can be obtained from $B_{z}$ which is generated by the driver coil. The results of the amplitude of $B_{z}$ as a function of $d$ for three different liftoffs and for three different plate's thicknesses are shown in Fig. 3 a) and b), respectively. In these FEM results, the amplitude of $B_{z}$ is computed as follows:

$$
\left|\mathrm{B}_{\mathrm{z}}\right|=\sqrt{\operatorname{real}\left(\mathrm{B}_{\mathrm{z}}\right)^{2}+\operatorname{imag}\left(\mathrm{B}_{\mathrm{z}}\right)^{2}}
$$

and the approximate amplitude of $\mathrm{V}_{\mathrm{s}}$ can be computed as

$$
\left|\mathrm{V}_{\mathrm{s}}\right|=\mathrm{NA}_{\mathrm{i}} \omega\left|\mathrm{B}_{\mathrm{z}}\right|
$$

where $\mathrm{N}$ represents the number of turns of the pickup coil, $\mathrm{A}_{\mathrm{i}}$ represents the area created by the inner loop of the pickup coil (i.e., $A_{i}=\pi\left(a_{1 p}\right)^{2}$ ) and $\omega$ is the angular frequency, in $\mathrm{rad} / \mathrm{s}$, at which the driver coil is excited (i.e., $\omega=2 \pi f$ ).

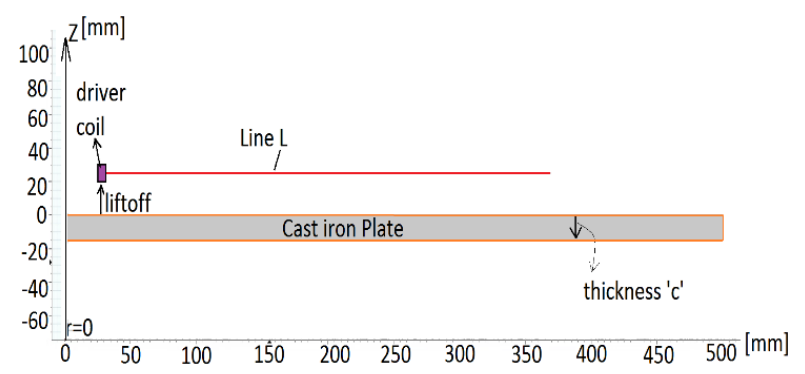

Fig. 22D Axisymmetric model used in Comsol

According to these results for $B_{z}$, the amplitude of $B_{z}$ is sensitive to the liftoff for $50 \mathrm{~mm}<\mathrm{d}<200 \mathrm{~mm}$ and its sensitivity to the liftoff, $\frac{\Delta \mathrm{B}_{\mathrm{Z}}}{\Delta \text { liftoff, }}$, decreases for $\mathrm{d}>200 \mathrm{~mm}$ (and $\frac{\Delta \mathrm{V}_{\mathrm{S}}}{\Delta \text { liftoff }}$ also decreases for $d>200 \mathrm{~mm}$ ). On the contrary, the sensitivity of the amplitude of $B_{z}$ to changes in the plate's thickness, $\frac{\Delta B_{z}}{\Delta c}$, increases for $\mathrm{d}>200 \mathrm{~mm}$ (and $\frac{\Delta V_{s}}{\Delta c}$ also increases for $\mathrm{d}>200 \mathrm{~mm}$ ). Ideally, the probe should have $\frac{\Delta \mathrm{B}_{\mathrm{Z}}}{\Delta \mathrm{c}}>>\frac{\Delta \mathrm{B}_{\mathrm{Z}}}{\Delta \text { liftoff }}$ (or $\frac{\Delta \mathrm{V}_{\mathrm{S}}}{\Delta \mathrm{c}}>>\frac{\Delta \mathrm{V}_{\mathrm{S}}}{\Delta \text { liftoff }}$ ), consequently the pickup coil should be located at a distance $\mathrm{d}>200 \mathrm{~mm}$. For example, at $\mathrm{d}=200 \mathrm{~mm},\left|\mathrm{~B}_{\mathrm{z}}\right| \cong 7 \mathrm{uT}$ (see Fig. 3 ) and using (2) we can estimate $\left|V_{s}\right|<300 \mathrm{uV}$. However, the amplitude of $B_{z}$ decreases as $d$ is further increased as shown in Fig. 3. Since $V_{s}$ is linearly dependent on $\left|B_{z}\right|$ as indicated in (2), then the voltage $\mathrm{V}_{\mathrm{s}}$ is expected to be small (smaller than $300 \mathrm{uV}$ for $\mathrm{d}>200 \mathrm{~mm}$ ) and buried in a noisy environment. These are the main reasons why we have implemented a lock-in amplifier to recover $\mathrm{V}_{\mathrm{s}}$. The details of the lock-in amplifier are presented in the following section (Section III).

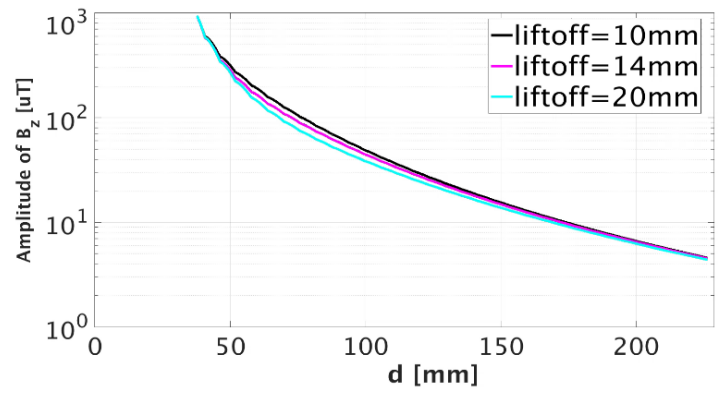

(a)

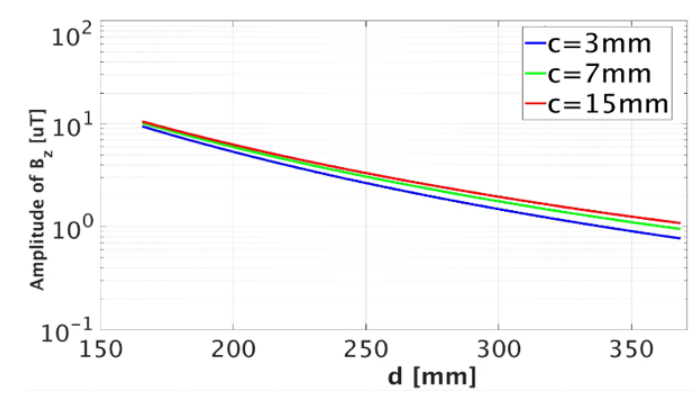

(b)

Fig. 3 Amplitude of $B_{z}$ as a function of $d$ for three different: a) liftoffs (plate's thickness is $13 \mathrm{~mm}$ ), b) thicknesses (liftoff is $20 \mathrm{~mm}$ ) 


\section{THE LOCK-IN AMPLIFIER}

The block diagram of the implemented dual-phase lock-in amplifier is shown in Fig. 4. The input of the lock-in amplifier is $\mathrm{V}_{\mathrm{r}}(\mathrm{t})$, and the two DC outputs are $\mathrm{X}$ and $\mathrm{Y}$. The signal received in the pickup coil, $\mathrm{V}_{\mathrm{r}}(\mathrm{t})$, is amplified by a factor $\mathrm{K}$ before being demodulated. The final stage consists of two lowpass filters (LPFs) that can be used to obtain the DC components $\mathrm{X}$ and $\mathrm{Y}$ from which we can estimate the amplitude of $\mathrm{V}_{\mathrm{s}}(\mathrm{t})$ and its phase (i.e., $\mathrm{A}$ and $\emptyset$ ).

In order to single out $\mathrm{V}_{\mathrm{s}}$ from the noise $\mathrm{n}(\mathrm{t})$, we need to provide a reference signal $\mathrm{V}_{\text {ref }}(\mathrm{t})$ that shares the same frequency with $\mathrm{V}_{\mathrm{s}}$. We can select for example a reference signal given by

$$
\mathrm{V}_{\text {ref }}(\mathrm{t})=\sin (\omega \mathrm{t}) \text {. }
$$

Assuming that $\mathrm{n}(\mathrm{t})$ can be represented as a linear combination of sinusoidal waves, then we can approximate the amplified voltage in the pickup coil as

$$
\mathrm{V}_{\mathrm{r}}(\mathrm{t})=\mathrm{AKsin}(\omega \mathrm{t}+\emptyset)+\sum_{\mathrm{i}=0}^{\infty} \mathrm{B}_{\mathrm{i}} \mathrm{K} \sin \left(\omega_{\mathrm{i}} \mathrm{t}+\theta_{\mathrm{i}}\right) .
$$

By multiplying (3) and (4), we obtain the output of the first demodulator as

$$
\begin{array}{r}
\mathrm{V}_{\mathrm{d} 1}(\mathrm{t})=\frac{\mathrm{AK}}{2}[\cos (\varnothing)-\cos (2 \omega \mathrm{t}+\emptyset)+ \\
\sum_{\mathrm{i}=0}^{\infty} \frac{\mathrm{B}_{\mathrm{i}} \mathrm{K}}{2}\left[\cos \left(\left(\omega_{\mathrm{i}}-\omega\right) \mathrm{t}+\theta_{\mathrm{i}}\right)-\right. \\
\left.\cos \left(\left(\omega_{\mathrm{i}}+\omega\right) \mathrm{t}+\theta_{\mathrm{i}}\right)\right]
\end{array}
$$

Due to the randomness of the noise, we can assume that in general $\omega_{i} \neq \omega$, and if we suppress the high frequencies of $\mathrm{V}_{\mathrm{d} 1}$ by using a LPF, the output $\mathrm{X}$ of the first LPF can be approximated as

$$
X=\frac{\mathrm{AK}}{2} \cos (\varnothing)
$$

Similarly, if $\mathrm{V}_{\mathrm{ref}}(\mathrm{t})=\cos (\omega \mathrm{t})$ and we multiply it by (4), we obtain the output of the second demodulator as

$$
\begin{array}{r}
\mathrm{V}_{\mathrm{d} 2}(\mathrm{t})=\frac{\mathrm{AK}}{2}[\sin (\varnothing)-\sin (2 \omega \mathrm{t}+\emptyset)+ \\
\sum_{\mathrm{i}=0}^{\infty} \frac{\mathrm{B}_{\mathrm{i}} \mathrm{K}}{2}\left[\sin \left(\left(\omega_{\mathrm{i}}-\omega\right) \mathrm{t}+\theta_{\mathrm{i}}\right)-\right. \\
\left.\sin \left(\left(\omega_{\mathrm{i}}+\omega\right) \mathrm{t}+\theta_{\mathrm{i}}\right)\right]
\end{array}
$$

And if we use a second LPF to suppress the high frequencies of $\mathrm{V}_{\mathrm{d} 2}$, the output $\mathrm{Y}$ of the second LPF can be approximated as

$$
\mathrm{Y}=\frac{\mathrm{AK}}{2} \sin (\varnothing)
$$

Finally, A and $\varnothing$ can be estimated from (6) and (8) as follows:

$$
\begin{aligned}
& A=\frac{2}{K} \sqrt{X^{2}+Y^{2}} \\
& \varnothing=\tan ^{-1}\left(\frac{Y}{X}\right) .
\end{aligned}
$$

Since the frequency of operation of the coils is $10 \mathrm{~Hz}$, it is difficult with analog LPFs to obtain a clear DC output. According to (5) and (7), ripple signals with a frequency of $2 \omega$ will be mixed with the DC outputs and the amplitude of the ripple will depend on the roll-off of the LPF. Besides the problem of the ripple signals, the analog LPF will have a slow response to changes in the signal because the cutoff frequency $\mathrm{f}_{\mathrm{c}}$ is small (i.e., the time constant of the lock-in amplifier $\tau=$ $\frac{1}{2 \pi f_{c}}$ is long).

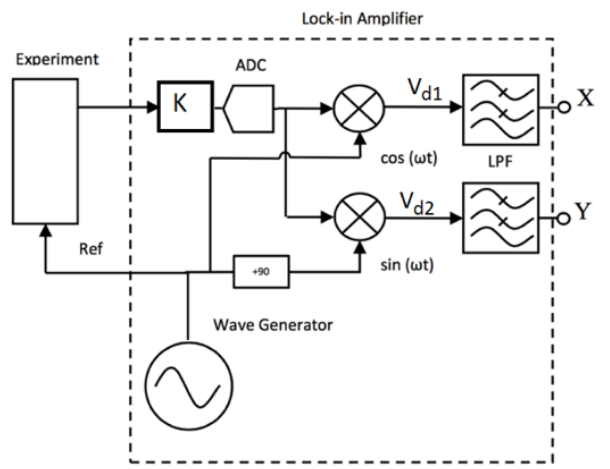

Fig. 4. Digital dual-phase lock-in amplifier. $\mathrm{V}_{\mathrm{d} 1}$ and $\mathrm{V}_{\mathrm{d} 2}$ represent the outputs of the demodulators

To overcome the issue of the ripple generated when using first-order LPFs, we could use higher-order LPFs to improve the roll-off and thus minimize the amplitude of the ripple signal. However, this approach would increase the complexity of the system and the system would still respond very slowly before the DC signal stabilizes as $\tau$ is determined by $f_{c}$.

The importance of the ripple and the response time $\tau$ depends on the particular application. In our application, minimizing the amplitude of the ripple is the most important factor to obtain greater accuracy and sensitivity to changes in the liftoff and thickness of the plate. Therefore, we have decided to demodulate $\mathrm{V}_{\mathrm{r}}(\mathrm{t})$ and also implement the LPFs in software. To this end, we firstly compute the fast Fourier transform (FFT) of $V_{d 1}(t)$ and $V_{d 2}(t): V_{d 1}(f)$ and $V_{d 2}(f)$, respectively. Secondly, we extract their DC components which correspond to the amplitudes at $\mathrm{f}=0 \mathrm{~Hz}$ (i.e., $2^{*}|\mathrm{X}|=\left|\mathrm{V}_{\mathrm{d} 1}(\mathrm{f}=0)\right|$ and $2 *$ $\left.|\mathrm{Y}|=\left|\mathrm{V}_{\mathrm{d} 2}(\mathrm{f}=0)\right|\right)$. Finally, we use (9) and (10) to estimate the amplitude and phase of $\mathrm{V}_{\mathrm{s}}(\mathrm{t})$. Besides the software implementation, we have implemented in hardware the amplification stage which consists of two op-amps in cascade to adjust the gain $\mathrm{K}$ and the details of the experimental setup are described in the next section (Section IV).

\section{EXPERIMENTAL RESULTS}

We fabricated the driver-pick up coil system with the parameters described in Section II. The two bobbins were fabricated in a 3D printer and mounted on 3 different plastic platforms (each platform with a fix d) as shown in Fig. 5. In our experiments, we varied the liftoff, the separation distance $d$ and the frequency of the driver coil. Three pairs of small plastic blocks with heights of 10,15 and $20 \mathrm{~mm}$ were placed under the coils to adjust the liftoff of the probe. We carried out our experiments on a $12 \mathrm{~mm}$ thick cast iron plate with an area of $600 \times 1500 \mathrm{~mm}^{2}$. The coils were placed in the centre of the plate to minimize the edge effects on the measurements.

A two-stage cascaded circuit with op-amps was used to amplify $\mathrm{V}_{\mathrm{r}}(\mathrm{t})$. The first stage consisted of a differential amplifier (AD620) and the second stage was used as a non- 
inverting amplifier (OP27). The driver coil was excited with a sinusoidal wave of $120 \mathrm{mV}$ generated in a PC that was amplified 100 times with a non-inverting amplifier (OPA548). A data acquisition unit (DAQ, NI USB-6221) was used to collect the data from the pickup coil and also to excite the driver coil.

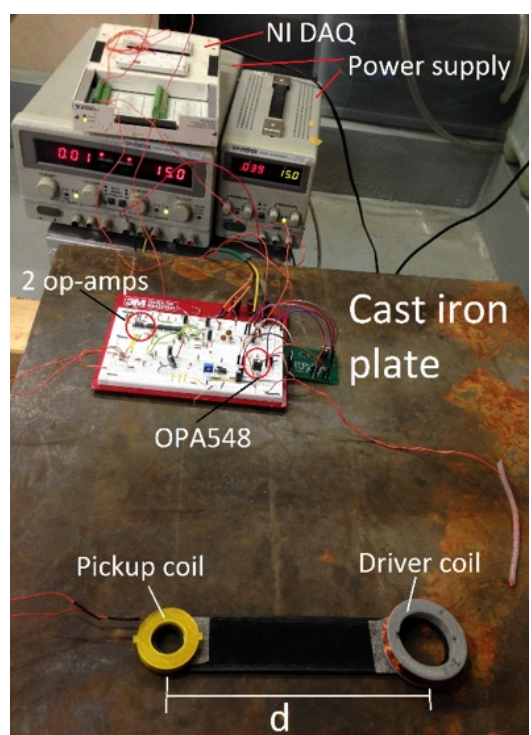

Fig. 5. Experimental setup. The platform in this figure that holds the coils has a separation distance of $\mathrm{d}=195 \mathrm{~mm}$. Two other plastic platforms were used with $\mathrm{d}=260$ and $340 \mathrm{~mm}$

In the first set of experiments, we aimed to characterize the noise in the system. To this end, we connected the pickup coil to the output of the differential amplifier which was set with a gain of 1 . The coils were tested in the air at a distance $d$ of 340 $\mathrm{mm}$ and the driver coil was excited at $10 \mathrm{~Hz}$. The voltage across the pickup coil in the time and frequency domains is shown in Fig. 6. The maximum amplitude of $\mathrm{V}_{\mathrm{r}}$ was estimated to be approximately $39 \mathrm{mV}$ at $10 \mathrm{~Hz}$ and the amplitudes of the rest of harmonics were less than $10 \mathrm{mV}$ as shown in Fig. $6 \mathrm{~b}$ ). We repeated this experiment for $\mathrm{d}=180,260$ and $340 \mathrm{~mm}$ and for 5 different frequencies. We always obtained the highest amplitudes at the same frequencies of the excitation signal and the amplitudes of the harmonics were always smaller. The results of these experiments are shown in Fig. 7 which only shows the maximum amplitudes of $\mathrm{V}_{\mathrm{r}}$.

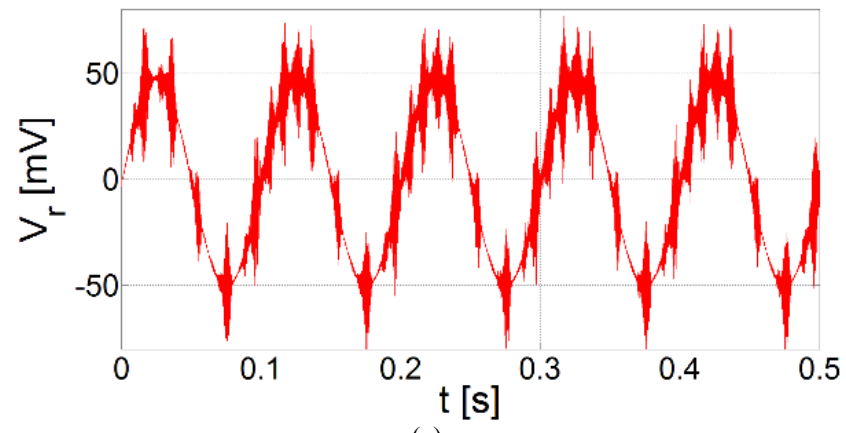

(a)

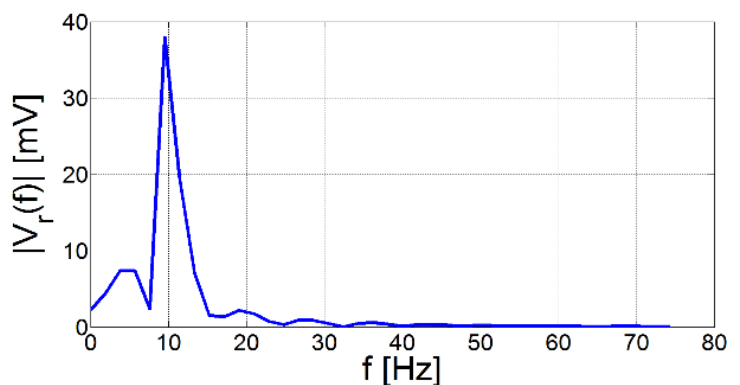

(b)

Fig. 6. $\operatorname{Vr}(\mathrm{t})$ : a) time domain, b) frequency domain (computed by using the FFT)

According to the results shown in Fig. $7,\left|V_{\mathrm{r}}\right| \cong 39 \mathrm{mV}$ for any $\mathrm{d}$ and $\mathrm{f}$ such $180 \mathrm{~mm}<\mathrm{d}<340 \mathrm{~mm}$ and $10 \mathrm{~Hz}<\mathrm{f}<50 \mathrm{~Hz}$. Considering that $\left|\mathrm{V}_{\mathrm{s}}\right|<300 \mathrm{uV}$ when $\mathrm{d}>200 \mathrm{~mm}$ at $10 \mathrm{~Hz}$ (as presented in Section II), we conclude that the voltage across the pickup coil $\mathrm{V}_{\mathrm{r}}$ is mainly due to noise. Therefore, $\mathrm{V}_{\mathrm{s}}$ is buried in noise $\mathrm{n}(\mathrm{t})$ that has an amplitude of approximately $39 \mathrm{mV}$ at the same frequency of the excitation signal and its harmonics have smaller amplitudes.

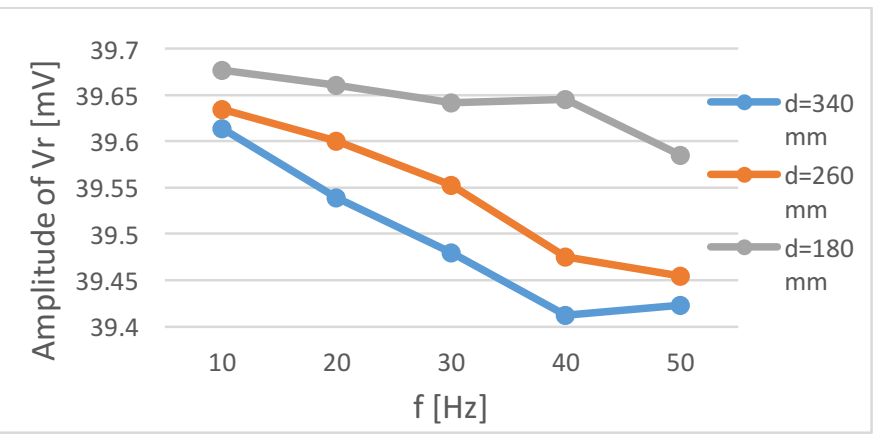

Fig. 7. Amplitude of $V_{r}$ estimated at the same frequency of excitation. $V_{r}$ is predominantly noise induced at the pickup coil

Since the amplitude of the noise at $10 \mathrm{~Hz}$ was estimated to be approximately $39 \mathrm{mV}$, then the magnitude of $\mathrm{V}_{\mathrm{s}}$ should be larger than $40 \mathrm{mV}$ to reduce the influence of the noise at the output of the lock-in amplifier and to enhance the sensitivity of the system. For these two reasons, in our second set of experiments, we put the two coils with a separation distance of $340 \mathrm{~mm}$ in the air and set up the AD620 with a gain of 1000 and the OP27 with a gain of 100 . With these gains, the amplitude of the amplified $\mathrm{V}_{\mathrm{s}}$ would be greater than $2 \mathrm{~V}$ but smaller than $10 \mathrm{~V}$ to avoid the saturation of the op-amps. The output of $\mathrm{V}_{\mathrm{r}}$ after being amplified by approximately $1.08 \mathrm{e} 5$ times is shown in Fig. 8.

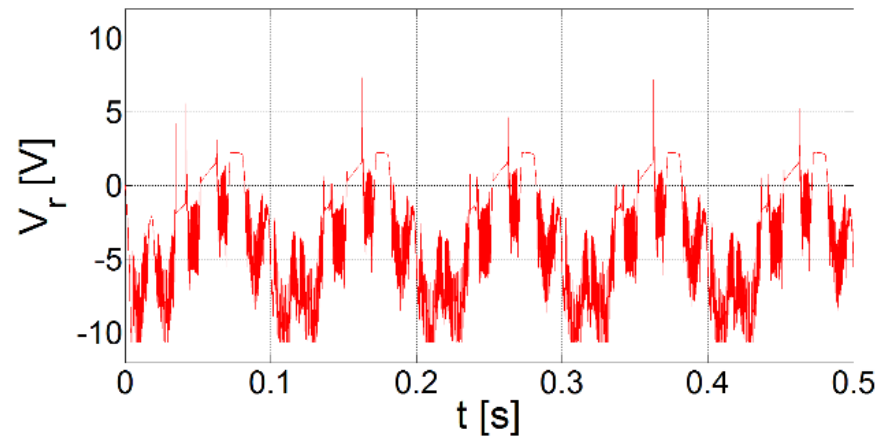

(a) 


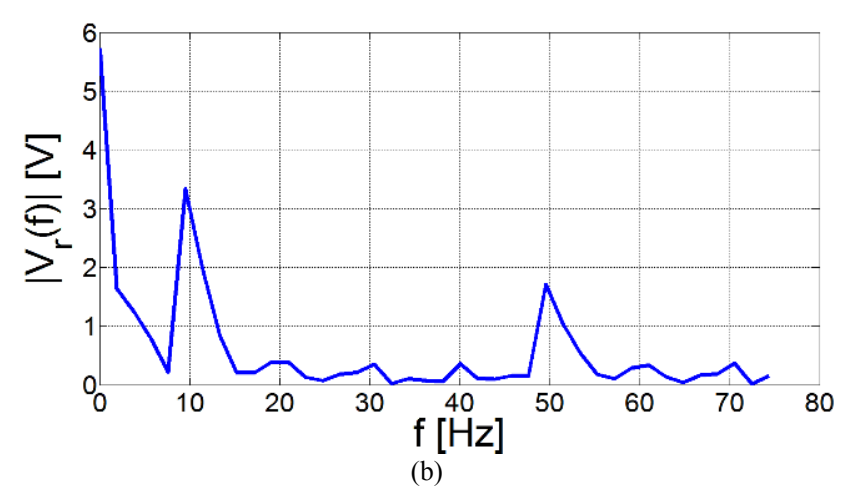

Fig. $8 . \operatorname{Vr}(\mathrm{t})$ amplified by $1.08 \mathrm{e} 5$ times: a) time domain, b) frequency domain

In Fig. 8 a), the first $100 \mathrm{~ms}$ differs from the other four cycles of $V_{r}$ due to a transient response. Therefore, only the last four cycles of $\mathrm{V}_{\mathrm{r}}$ were considered to compute the FFT and the amplitude of $V_{r}$ in the frequency domain is shown in Fig. 8 b).

This $\mathrm{V}_{\mathrm{r}}$ was passed through the lock-in amplifier which estimated an output of $3.4 \mathrm{~V}$ (i.e., $3.4=2 \sqrt{X^{2}+Y^{2}}$ ). By using (9), and subtracting the amplitude of the noise of $39 \mathrm{mV}$, we have estimated an amplitude $\mathrm{A}=31 \mathrm{uV}(31 \mathrm{uV}=(3.4-0.039) /$ *1.08e5). Thus, the lock-in amplifier is able to pick up $\left|\mathrm{V}_{\mathrm{s}}\right|=31$ $\mathrm{uV}$ even when there is noise of $39 \mathrm{mV}$ at the same frequency. This represents an improvement in the SNR of at least $30 \mathrm{db}$.

In the final set of experiments, we tested the pair of coils above a cast iron plate with a constant thickness of $12 \mathrm{~mm}$ and only varied the liftoff and the distance $d$. The aim of these final experiments is to validate if the sensitivity of $\mathrm{V}_{\mathrm{s}}$ to the liftoff, $\frac{\Delta V_{S}}{\Delta l \text { liftoff }}$, decreases as discussed in Section II. In the first experiment, we placed the coils at $\mathrm{d}=340 \mathrm{~mm}$, liftoff $=10 \mathrm{~mm}$ and excited the driver coil at $10 \mathrm{~Hz}$. The total gain with the two op-amps was set to $\mathrm{K}=24390$ (differential amplifier with a gain of 1074) to obtain an amplified $\mathrm{V}_{\mathrm{r}}$ in the range between $1 \mathrm{~V}$ and 10 V. Fig. 9 shows the output of the demodulators in the frequency domain.

We obtained: $2 * X=-0.255 * 2=-0.51 \mathrm{~V}\left(\left|\mathrm{~V}_{\mathrm{d} 1}(\mathrm{f}=0)\right|=0.51 \mathrm{~V}\right.$ as shown in Fig. 9 a)), $2 * Y=-0.85 * 2=-1.7\left(\left|\mathrm{~V}_{\mathrm{d} 2}(\mathrm{f}=0)\right|=1.7 \mathrm{~V}\right.$ as shown in Fig. 9 b)), $2 * \sqrt{\mathrm{X}^{2}+\mathrm{Y}^{2}}=1.77 \mathrm{~V}$. Thus, the amplitude of $\mathrm{V}_{\mathrm{s}}$ is $\mathrm{A}=71.1 \mathrm{uV}((1.77-0.039) / \mathrm{K})$. We repeated this experiment for three different liftoffs $(10,15$ and $20 \mathrm{~mm})$, carrying out eight experiments for each liftoff, and for three different separation distances (195, 260 and $340 \mathrm{~mm})$. Thus, a total of 72 experiments were conducted. The total gain $\mathrm{K}$ was adjusted to 11802 for $\mathrm{d}=195$ and $260 \mathrm{~mm}$ to make sure that the amplified signal $\mathrm{V}_{\mathrm{r}}$ was larger than $1 \mathrm{~V}$ but smaller than $10 \mathrm{~V}$. Fig. $10 \mathrm{a}$ ) and b) show the output of the lock-in amplifier (i.e., $2 * \sqrt{\mathrm{X}^{2}+\mathrm{Y}^{2}}$ ) for $\mathrm{d}=260 \mathrm{~mm}$ and $\mathrm{d}=340 \mathrm{~mm}$, respectively. We also averaged the output of the lock-in amplifier and subtracted the noise (the $39 \mathrm{mV}$ ) from it to estimate the amplitude of $V_{\mathrm{s}}$. These results are summarized in Table I.

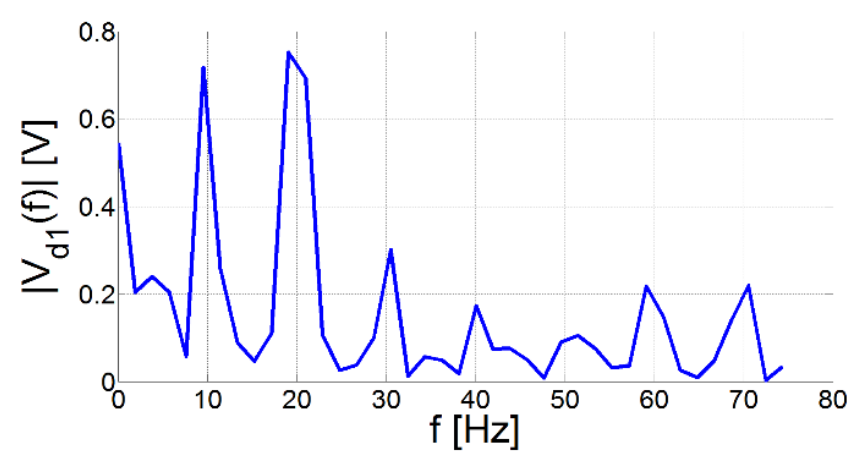

(a)

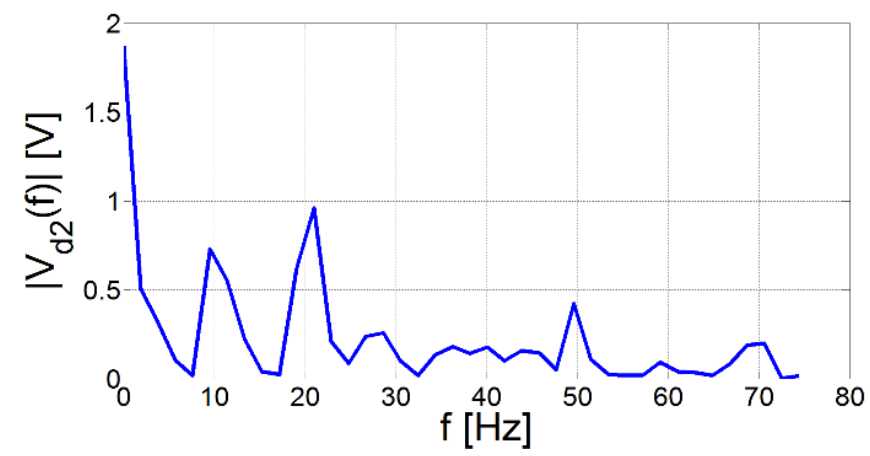

(b)

Fig. 9. Output of demodulators in the frequency domain. The gain of the opamps was set up to $K=24390$

According to the experimental results in Table I, $\frac{\Delta \mathrm{V}_{\mathrm{S}}}{\Delta \text { liftoff }}=4.7$ $\mathrm{uV} / \mathrm{mm}$ for $\mathrm{d}=195 \mathrm{~mm}$, and $\frac{\Delta \mathrm{V}_{\mathrm{s}}}{\Delta \text { liftoff }}$ decreases to $0.45 \mathrm{uV} / \mathrm{mm}$ for $\mathrm{d}=340 \mathrm{~mm}$. These experimental results are in agreement with those obtained from Comsol which are presented in Section II and indicate that the probe would be less sensitive to changes in the liftoff as $d$ increases. We also expect that the probe is more sensitive to changes in the thickness of the plate as $\mathrm{d}$ increases (i.e., $\frac{\Delta \mathrm{V}_{\mathrm{s}}}{\Delta \mathrm{c}} \uparrow$ as $\mathrm{d} \uparrow$ ). Although $\frac{\Delta \mathrm{V}_{\mathrm{s}}}{\Delta \mathrm{c}}$ was not experimentally measured in this work for different separation distances, it will be the focus of our future work.

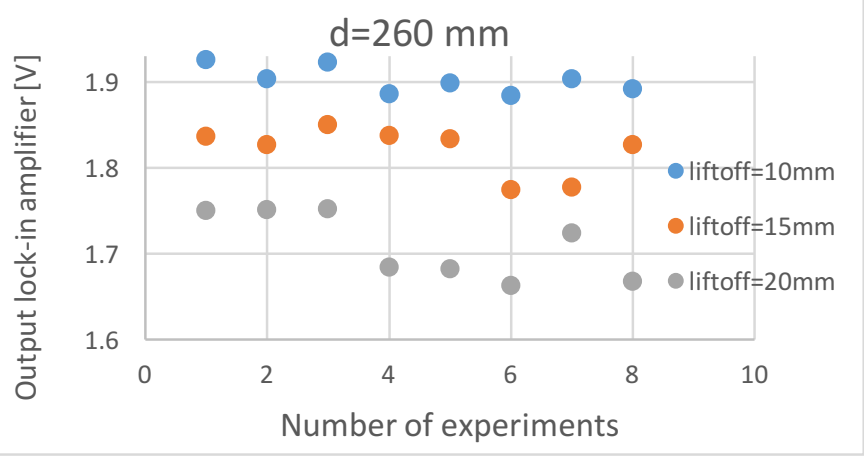

(a) 


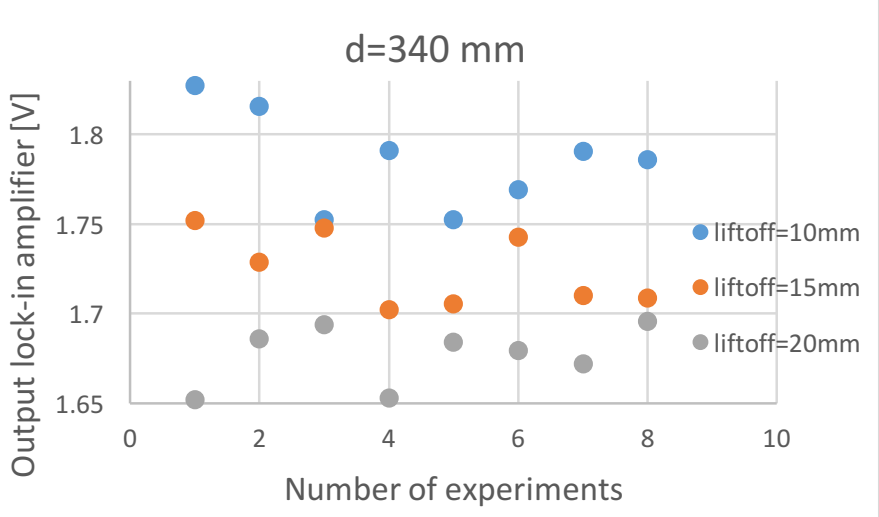

(b)

Fig. 10. Output of the lock-in amplifier for: a) $d=260 \mathrm{~mm}$, b) $d=340 \mathrm{~mm}$

Table I. Amplitude of $\mathrm{V}_{\mathrm{s}}(\mathrm{t})$ in $\mathrm{uV}$

\begin{tabular}{|c|c|c|c|}
\hline $\begin{array}{c}\text { liftoff } \\
{[\mathrm{mm}]}\end{array}$ & $\begin{array}{c}\mathrm{d}=195 \\
{[\mathrm{~mm}]}\end{array}$ & $\begin{array}{c}\mathrm{d}=260 \\
{[\mathrm{~mm}]}\end{array}$ & $\begin{array}{c}\mathrm{d}=340 \\
{[\mathrm{~mm}]}\end{array}$ \\
\hline 10 & 349.5 & 157.8 & 71.6 \\
\hline 15 & 304.8 & 150.9 & 69.1 \\
\hline 20 & 302.8 & 141.5 & 67.1 \\
\hline
\end{tabular}

\section{CONCLUSIONS AND FUTURE WORK}

We have presented in this work a lock-in amplifier as part of a signal processing technique that is to operate with a probe to perform non-destructive inspections. We have shown that the lock-in amplifier is able to recover small signals generated in a pickup coil that can be buried in a noisy environment. Specifically, we have found that a signal with an amplitude of $31 \mathrm{uV}$ can be recovered even when the noise is 1000 times larger at the same frequency of operation. This improvement in the SNR obtained by using the lock-in amplifier also provides an enhancement of the sensitivity of the probe. By tuning the lock-in amplifier through changes in the total gain of the opamps, we were able to obtain a sensitivity of $0.45 \mathrm{uV} / \mathrm{mm}$. The experimental results, which are in agreement with the theoretical results, indicate that a properly tuned lock-in amplifier can be potentially used to measure variations in the thickness of cast iron plates, although this work is left for our future work.

\section{REFERENCES}

[1] B. A. Auld, and J. C. Moulder, "Review of Advances in Quantitative Eddy Current Nondestructive Evaluation", Journal of Nondestructive Evaluation, vol. 18, No. 1, 1999.

[2] M.Ph. Papaelias, C. Roberts, and C.L. Davis, "A review on nondestructive evaluation of rails: State-of-the-art and future development", Proceedings of the Institution of Mechanical Engineers, Part F: Journal of Rail and Rapid Transit, vol. 222, Issue 4, pp. 367-384, 2008.

[3] C. Ye, J. Xin, Z. Su, L. Udpa, and S. S. Udpa, "Novel Transceiver Rotating Field Nondestructive Inspection Probe", IEEE Transactions on Magnetics, vol. 51, No. 7, Jul. 2015.

[4] R. Falque, T. Vidal-Calleja, J. V. Miro, D. C. Lingnau, and D. E. Russell, "Background Segmentation to Enhance Remote Field Eddy Current Signals", Australasian Conference on Robotics and Automation, Melbourne, Australia, Dec 2-4 2014.

[5] S. M. Haugland, "Fundamental Analysis of the Remote-Field EddyCurrent Effect", IEEE Transactions on Magnetics, vol. 32, No. 4, Jul. 1996.

[6] Y. S. Sun, S. Udpa, W. Lord, and D. Cooley, "Inspection of Metallic Plates Using a Novel Remote Field Eddy Current NDT Probe", Review of Progress in Quantitative Nondestructive Evaluation, vol. 15, pp. 11371144, 1996.

[7] Y.S. Sun, W. Lord, L. Udpa, S. Udpa, S.K. Lua, and K.H. Ng, "Thickwalled Aluminum Plate Inspection Using Remote Field Eddy Current Techniques", Review of Progress in Quantitative Nondestructive Evaluation, vol. 16, pp. 1005-1012, 1997.

[8] S. K. Burke, and M. E. Ibrahim, "Mutual impedance of air-cored coils above a conducting plate", Journal of Physics D: Appl. Phys., vol. 37, pp. $1857-1868,2004$.

[9] R. Falque, T. Vidal-Calleja, G. Dissanayake, and J. V. Miro, "From the Skin-Depth Equation to the Inverse RFEC Sensor Model", International Conference on Control, Automation, Robotics and Vision, Phuket, Thailand, Nov. 13-15, 2016.

[10] X. Xu and F. Luo, "Optimal sensor design and digital signal processing techniques for remote field eddy current testing", Insight: NonDestructive Testing and Condition Monitoring, vol. 48, No. 7, pp. 421425, Jul. 2006.

[11] J. Isla, and F. Cegla, "Coded Excitation for Low SNR Pulse-Echo Systems: Enabling Quasi-Real-Time Low-Power EMATs", IEEE International Ultrasonics Symposium, Tours, France, Sep. 18-21 2016. 